\title{
Article
}

\section{Switching the Spin State of Pentafluorophenylnitrene: Isolation of a Singlet Arylnitrene Complex}

Joel Mieres-Perez, Paolo Costa, Enrique Mendez-Vega, Rachel Crespo-Otero, and Wolfram Sander

J. Am. Chem. Soc., Just Accepted Manuscript • DOI: 10.1021/jacs.8b10792 • Publication Date (Web): 15 Nov 2018

Downloaded from http://pubs.acs.org on November 16, 2018

\section{Just Accepted}

"Just Accepted" manuscripts have been peer-reviewed and accepted for publication. They are posted online prior to technical editing, formatting for publication and author proofing. The American Chemical Society provides "Just Accepted" as a service to the research community to expedite the dissemination of scientific material as soon as possible after acceptance. "Just Accepted" manuscripts appear in full in PDF format accompanied by an HTML abstract. "Just Accepted" manuscripts have been fully peer reviewed, but should not be considered the official version of record. They are citable by the Digital Object Identifier (DOI®). "Just Accepted" is an optional service offered to authors. Therefore, the "Just Accepted" Web site may not include all articles that will be published in the journal. After a manuscript is technically edited and formatted, it will be removed from the "Just Accepted" Web site and published as an ASAP article. Note that technical editing may introduce minor changes to the manuscript text and/or graphics which could affect content, and all legal disclaimers and ethical guidelines that apply to the journal pertain. ACS cannot be held responsible for errors or consequences arising from the use of information contained in these "Just Accepted" manuscripts. 


\title{
Switching the Spin State of Pentafluorophenylnitrene: Isolation of a Singlet Arylnitrene Complex
}

\author{
Joel Mieres-Perez ${ }^{+1}$, Paolo Costa $^{+1}$, Enrique Mendez-Vega $^{\dagger}$, Rachel Crespo-Otero $^{\ddagger}$, Wolfram Sander $^{{ }^{*}}$ \\ ${ }^{\dagger}$ Lehrstuhl für Organische Chemie II, Ruhr Universität Bochum, 44780 Bochum, Germany \\ ${ }^{\ddagger}$ School of Biological and Chemical sciences, Queen Mary University London, Mile End Road, London E1 4NS, UK \\ Supporting Information Placeholder
}

\begin{abstract}
The chemistry of arylnitrenes is dominated by their triplet ground states and excited open-shell singlet states. This results in radical-type reactions and unwanted rearrangements which diminish the use of arylnitrenes as intermediates in organic synthesis. While the closed-shell singlet states of arylnitrenes are expected to undergo useful chemical transformations (comparable to the closed shell singlet states of carbenes), these states are too high in energy to be chemically accessible. When triplet pentafluorophenylnitrene is interacting with the Lewis acid $\mathrm{BF}_{3}$ under the conditions of matrix isolation, a Lewis acid-base complex consisting of the closed-shell singlet state of the nitrene and two molecules of $\mathrm{BF}_{3}$ is formed. Although the closed shell singlet state of pentafluorophenylnitrene is calculated (CCSD $\left.(\mathrm{T})\right)$ to lie more than 25 $\mathrm{kcal} / \mathrm{mol}$ above its triplet ground state, the reaction with $\mathrm{BF}_{3}$ results in switching the spin state from triplet to singlet. The formation of the singlet complex was monitored by IR, UV-vis, and EPR spectroscopy. DFT, CCSD(T), and CASPT2 calculations confirm the experimental findings.
\end{abstract}

\section{INTRODUCTION}

Aryl nitrenes ${ }^{1}$ are key intermediates in a large number of reactions which found applications in photoaffinity labelling, ${ }^{2-4}$ photolithography, ${ }^{3}$ and as building blocks for organic magnetic materials. ${ }^{5-7}$ The photochemical and thermal decomposition of arylazides as suitable precursors of arylnitrenes has therefore been extensively studied (Scheme 1). ${ }^{1,8-12}$ The chemistry of arylnitrenes is complex, since, although these nitrenes show robust triplet ground states, they are born as highly reactive, long-lived open-shell singlets from their precursors. The intersystem crossing rates are frequently low, and therefore openshell singlet reactivity (e. g. rearrangements) efficiently competes with the triplet ground state chemistry. ${ }^{13}$ In the related carbenes, most of the useful chemistry arises from closed-shell (zwitterionic) singlet states, e. g. insertion reactions, cycloadditions, Lewis base chemistry, or ylide formation. For nitrenes, the closed-shell singlet states are too high in energy to be chemically accessible. Here, we suggest a strategy to stabilize the closed-shell singlet states of nitrenes and to control the chemistry of these species via Lewis acid-base interactions.

Phenylnitrene $\mathbf{1 a}$ is conveniently produced by photolysis ${ }^{14}$ or flash vacuum pyrolysis ${ }^{15}$ of phenylazide $\mathbf{2 a}$. Nitrene $\mathbf{1 a}$ is highly labile and easily rearranges to the cyclic ketenimine $\mathbf{4 a}$ with azirine $\mathbf{3 a}$ as intermediate. ${ }^{1,16-17}$ The ground state of $\mathbf{1 a}$ was found to be triplet by EPR spectroscopy, ${ }^{14}$ and the singlet-triplet splitting $\left(\Delta \mathrm{E}_{\mathrm{ST}}\right)$ determined to $14.8 \mathrm{kcal} / \mathrm{mol}$ by negative ion photoelectron spectroscopy. ${ }^{18}$ The large $\Delta \mathrm{E}_{S \mathrm{~T}}$ in phenylnitrene is not much dependent on substituents in the phenyl ring, ${ }^{18-}$ ${ }^{19}$ in good agreement with predictions from high-level ab initio calculations. ${ }^{20}$

\footnotetext{
${ }^{1}$ Both authors contributed equally to this work.
} 
Scheme 1. Rearrangements of phenylnitrene $1 \mathrm{a}$.

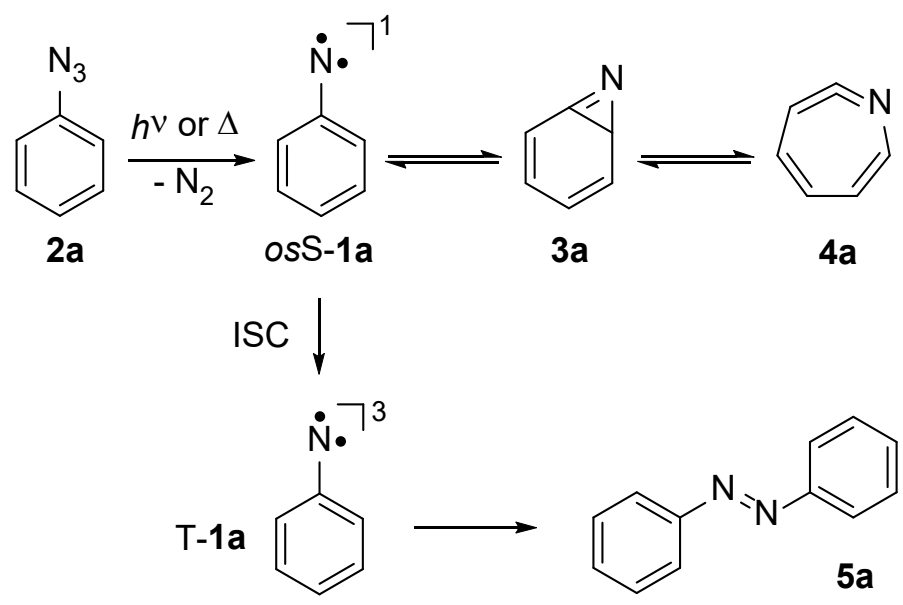

Singlet phenylnitrene S-1a is a transient species that was detected by laser flash photolysis showing an absorption maximum at $350 \mathrm{~nm}$ and a lifetime of approximately $1 \mathrm{~ns} .{ }^{21-22}$ The lowest-lying singlet state of $\mathbf{1 a}$ is the open-shell singlet state osS$\mathbf{1 a}\left({ }^{1} \mathrm{~A}_{2}\right)$, whereas the closed-shell singlet state csS-1a $\left({ }^{1} \mathrm{~A}_{1}\right)$ lies $30 \mathrm{kcal} / \mathrm{mol}$ above the triplet ground state $\mathrm{T}-\mathbf{1 a}\left({ }^{3} \mathrm{~A}_{2}\right) .{ }^{8,23}$ Characteristic of osS-1a is the delocalization of one of the unpaired electrons resulting in a short C-N bond distance. This resembles the electronic structure of the benzyl radical, and consequently, this state is stabilized by radical stabilizing substituents. Based on this hypothesis, Wenthold predicted $\Delta \mathrm{E}_{\mathrm{S}-\mathrm{T}}$ for 2 -furanylnitrene 6 to be $4.5 \mathrm{kcal} / \mathrm{mol}$ smaller than that in $1 \mathbf{a}^{24}$<smiles>CN(C)c1ccccc1</smiles>

$\mathrm{T}-1 \mathrm{a}$<smiles>[N]=C1C=CC=CC1</smiles><smiles>[131Sb]</smiles>

$\left({ }^{1} A_{2}\right)$<smiles>[N+]=[N+]c1ccccc1</smiles>

csS-1a

$\left({ }^{1} \mathrm{~A}_{1}\right)$

The only known singlet ground state nitrenes where the nitrene center is attached to a carbon atom are $\alpha$-oxonitrenes and related species, such as acylnitrenes. In these nitrenes, the closed-shell singlet state is stabilized by an oxazirine-like resonance structure. ${ }^{25}$ For the parent HCNO 7 in its singlet ground state the $\mathrm{C}-\mathrm{O}, \mathrm{C}-\mathrm{N}$, and $\mathrm{O}-\mathrm{N}$ bond lengths were calculated to 1.307, 1.260 , and $1.816 \AA$, respectively $(\mathrm{CCSD}(\mathrm{T}) / \mathrm{cc}-\mathrm{pVTZ})$, indicating a hybrid nitrene-oxazirine structure with a very strong $\mathrm{N} . . . \mathrm{O}$ interaction. ${ }^{26}$ Acylnitrenes are intermediates in the Curtius rearrangement, and several derivatives were detected by time-resolved spectroscopy ${ }^{27}$ or could be isolated in inert gas matrices. ${ }^{26}$ In a recent publication, Zeng et al. described that furoylnitrene 8 could be characterized in their singlet states in inert gas matrices, while in solid toluene at $10 \mathrm{~K}$ the triplet state was observed by EPR spectroscopy ${ }^{28}$ This indicates a very small singlet-triplet gap in $\mathbf{8}$, although it is not clear how the different matrix environments (argon vs. toluene) influences the gap. The singlet states of nitrenes are also stabilized when the nitrene center is attached to heteroatoms such as transition metals (metal-nitrido complexes), nitrogen (aminonitrenes) or phosphorus (phosphinonitrenes). ${ }^{29}$
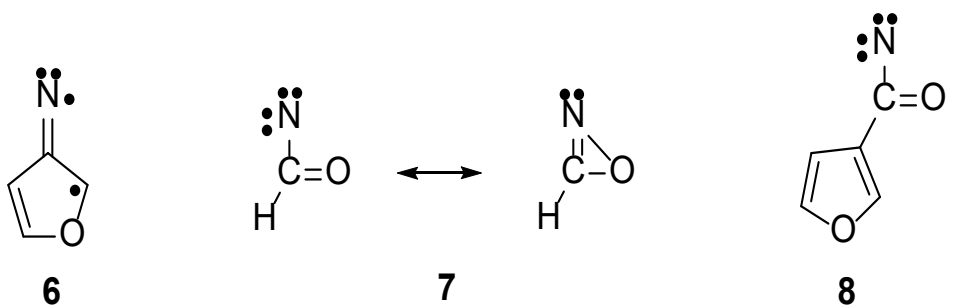

Recently, we demonstrated that the closed-shell singlet states of arylcarbenes such as diphenylcarbene 9 can be stabilized by interactions with Lewis acids such as water, ${ }^{30-31}$ methanol, ${ }^{32-33} \mathrm{CF}_{3} \mathrm{I}^{34}$ or $\mathrm{BF}_{3} \cdot{ }^{35}$ Thus, while the triplet ground state of diphenylcarbene T-9 lies approximately $5 \mathrm{kcal} / \mathrm{mol}$ below the closed-shell singlet state $\mathrm{S}-\mathbf{9}$, the singlet state becomes ground state upon interaction with a single molecule of water or methanol. This allowed us to isolate and spectroscopically 
characterize complexes of singlet states of carbenes that without interactions with the Lewis acids would be excited states. With $\mathrm{BF}_{3}$, zwitterion 10 is formed in a highly exothermic reaction. Zwitterion 10 consists of a positively charged benzhydryl and a negatively charged $\mathrm{BF}_{3}$ unit.

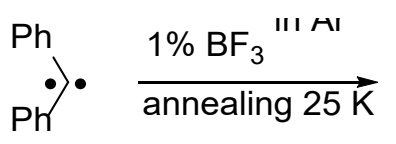

T-9

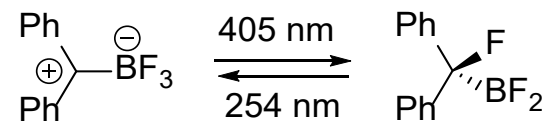

10

It is tempting to use the same method to stabilize the closed-shell singlet states of arylnitrenes by interactions of the nitrenes with Lewis acids. However, given the very large energy gaps between the triplet ground states and the closed-shell singlet states of arylnitrenes in the order of $30 \mathrm{kcal} / \mathrm{mol}$, only very strong Lewis acids such as $\mathrm{BF}_{3}$ could possibly switch the spin states of arylnitrenes. While reactions of arylazides with $\mathrm{BF}_{3}$ are well known, ${ }^{36}$ thorough mechanistic studies of reactions of arylnitrenes with $\mathrm{BF}_{3}$ are lacking. To suppress unwanted photochemical rearrangements of the arylnitrenes during their synthesis, we selected pentafluorophenlynitrene $\mathbf{1 b}$ as a suitable nitrene that can be synthesized in high yields by photolysis of the corresponding arylazide $\mathbf{2} \mathbf{b}$. Initial experiments with water, methanol, and $\mathrm{CF}_{3} \mathrm{I}$ confirmed our expectation that the singlet-triplet splitting of $\mathbf{1}$ is far too high to make the singlet state ground state by interaction with these molecules. Here, we describe the interaction of triplet nitrene $\mathrm{T}-\mathbf{1} \mathbf{b}$ with the strong Lewis acid $\mathrm{BF}_{3}$ that results in the formation of a closedshell singlet state nitrene complex.

\section{Results and Discussion}

IR experiments. Triplet pentafluorophenylnitrene $\mathrm{T}-\mathbf{1} \mathbf{b}$ was generated by $\lambda=254 \mathrm{~nm}$ irradiation of pentafluorophenylazide $\mathbf{2 b}$, matrix-isolated in argon at $3 \mathrm{~K}$. Under these conditions, high yields of nitrene $\mathrm{T}-\mathbf{1} \mathbf{b}$ are obtained and only small amounts of rearranged products. ${ }^{37}$ If the argon is doped with $1 \% \mathrm{BF}_{3}$, photolysis of $\mathbf{2} \mathbf{b}$ produces again high yields of $\mathrm{T}-\mathbf{1} \mathbf{b}$ as long as the matrix is kept at temperatures below $10 \mathrm{~K}$ to prevent diffusion of trapped molecules and thus bimolecular reactions (Figure 1). However, annealing of this matrix at $20 \mathrm{~K}$ for several min results in a decrease of the intensity of all IR bands assigned to $\mathrm{T}-\mathbf{1} \mathbf{b}$ and to $\mathrm{BF}_{3}$ monomer. In addition to the IR bands of the oligomers of $\mathrm{BF}_{3}$ at 1421,1472 and $1515 \mathrm{~cm}^{-1}$, two weak bands appear at 984 and $1031 \mathrm{~cm}^{-1}$ which are assigned to cis-1,2-bis(perfluorophenyl)diazene $\mathbf{5 b}$. Additionally, small shifts in the positions of the IR bands of T-1 $\mathbf{b}$ are observed as result of the relaxation of the matrix. Similar small shifts were observed if an argon matrix containing $\mathrm{T}-\mathbf{1} \mathbf{b}$ without $\mathrm{BF}_{3}$ was annealed at $20 \mathrm{~K}$ for $10 \mathrm{~min}$ (Figure S1, SI). 


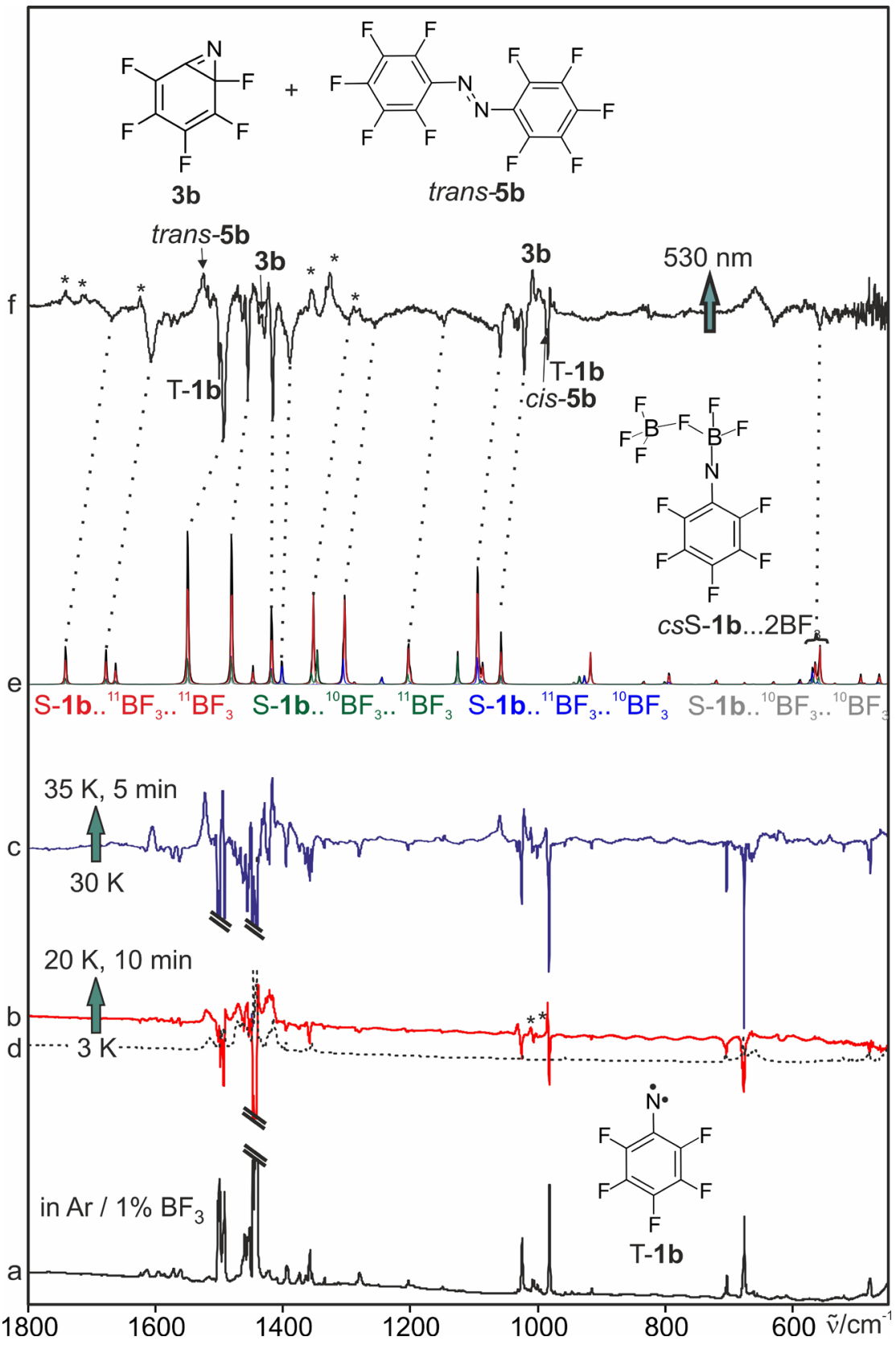

Figure 1. IR spectra showing the reaction of $\mathrm{T}-\mathbf{1} \mathbf{b}$ with $\mathrm{BF}_{3}$. a) IR spectrum of $\mathrm{T}-\mathbf{1} \mathbf{b}$ in an argon matrix doped with $1 \%$ of $\mathrm{BF}$ at $3 \mathrm{~K}$ generated by $\lambda=$ $254 \mathrm{~nm}$ photolysis of $\mathbf{2} \mathbf{b}$. b) Difference IR spectrum of the same matrix showing the changes after annealing at $20 \mathrm{~K}$ for $10 \mathrm{~min}$. Bands pointing downwards assigned to $\mathrm{T}-\mathbf{1} \mathbf{b}$ and $\mathrm{BF}_{3}$ are disappearing, and bands pointing upwards assigned to $\mathbf{5 b}$ and oligomers of $\mathrm{BF}_{3}$ are appearing. $\mathrm{c}$ ) Difference IR spectrum of the same matrix showing changes after annealing at $35 \mathrm{~K}$ for $5 \mathrm{~min}$. Bands pointing downwards assigned to $\mathrm{T}$-1 $\mathbf{1}$ are disappearing, and bands pointing upwards assigned to $\mathrm{S}-\mathbf{1 b}$...2 $2 \mathrm{BF}_{3}$ are appearing. $\mathrm{d}$ ) IR spectrum of an argon matrix containing $1 \%$ of $\mathrm{BF}_{3}$ annealed from $3 \mathrm{~K}$ to $20 \mathrm{~K}$ for 10 minutes. e) Calculated spectra of $c s S-1 \mathbf{b} \ldots 2 \mathrm{BF}_{3}$ at the $\mathrm{M} 06-2 \mathrm{X} / 6-311++\mathrm{G}(\mathrm{d})$ level of theory considering the natural abundancies of the boron isotopes. The black trace is the corresponding sum of the spectra of the different isotopes. $\mathrm{f}$ ) Difference IR spectrum showing changes after irradiation of the matrix with $\lambda=530 \mathrm{~nm}$ for $20 \mathrm{~min}$. Bands pointing downwards assigned to complex $\operatorname{csS}-\mathbf{1} \mathbf{b} \ldots 2 \mathrm{BF}, \mathrm{T}-\mathbf{1} \mathbf{b}$ and dimer cis-5b are disappearing. Bands pointing upwards correspond to $\mathbf{3 b}$, trans-5b and some unidentified products.

Interestingly, additional annealing of the matrix for several min at $35 \mathrm{~K}$ results in a characteristic change of the color of the matrix from colorless to red, (Figure S6, SI). During this annealing process, all IR bands corresponding to T-1 $\mathbf{b}$ and $\mathrm{BF}_{3}$ decrease in intensity and a new set of bands appears with the strongest absorptions at 1021.5, 1059 and $1605.6 \mathrm{~cm}^{-1}$ (Figure 1). If the matrix contained only $0.2 \%$ of $\mathrm{BF}_{3}$, annealing resulted in less coloration and smaller IR peaks of the new product (Figure S2, SI). This indicates that nitrene $\mathrm{T}-\mathbf{1} \mathbf{b}$ reacts with $\mathrm{BF}_{3}$, and that this reaction requires high concentrations and a high mobility (at temperatures above $20 \mathrm{~K}$ in argon) of $\mathrm{BF}_{3}$. The species formed by the interaction between $\mathrm{T}-\mathbf{1} \mathbf{b}$ and $\mathrm{BF}_{3}$ is photolabile, and irradiation with $\lambda=530 \mathrm{~nm}$ produces benzazirine $\mathbf{3 b}$ plus further IR bands of unidentified products. In 
addition, the trans form of $\mathbf{5 b}$ was found in the spectrum by comparison with an authentic matrix isolated sample. This selective photochemistry helped to identify IR bands of the new species.

The IR spectrum of the reaction product between $\mathrm{T}-\mathbf{1} \mathbf{b}$ and $\mathrm{BF}_{3}$ was compared to calculated spectra of a variety of possible reaction products. The best agreement was found for the closed-shell singlet nitrene csS-1b interacting with two $\mathrm{BF}_{3}$ molecules (Figure 1, Figure S3). In this singlet complex csS- $\mathbf{1 b} \ldots .2 \mathrm{BF}_{3}$, the two $\mathrm{BF}_{3}$ molecules interact via an unusual fluoronium bridge (Figure 1). The IR spectrum of $c s S-1 \mathbf{b} \ldots 2 \mathrm{BF}_{3}$ shows a weak IR band at $555 \mathrm{~cm}^{-1}$, which is assigned to the asymmetric B-F-B stretching vibration of the fluoronium bridge, (Table S1, see SI). A similar B-F-B bridge with a vibration at $537 \mathrm{~cm}^{-1}$ was recently reported for the complex between tetrachlorocyclopentadienylidene $\mathbf{1}$ and two molecules of $\mathrm{BF}_{3} \cdot{ }^{38}$

EPR experiments. The EPR spectrum of $\mathrm{T}-\mathbf{1} \mathbf{b}$ was recorded in argon doped with $1 \%$ of $\mathrm{BF}_{3}$ at $5 \mathrm{~K}$, under similar conditions as in the IR experiments. The intense transition at $713 \mathrm{mT}$ observed in the EPR spectrum (Figure S4) is typical for triplet arylnitrenes. Annealing at $20 \mathrm{~K}$ for $5 \mathrm{~min}$ and subsequent cooling to $3 \mathrm{~K}$ resulted in a loss of $10 \%$ of the EPR signal intensity of T-1b. A loss of about $50 \%$ of T-1b is found when the matrix is annealed at $30 \mathrm{~K}$ (Figure S4). During these annealing experiments the concentration of radical species increases only slightly, indicating that $\mathrm{T}-\mathbf{1 b}$ reacts with $\mathrm{BF}_{3}$ to form a diamagnetic species.

UV-vis Experiments. Pentafluorophenylazide $\mathbf{2 b}$ was co-deposited with argon doped with $1 \%$ of $\mathrm{BF}_{3}$ onto a sapphire window cooled at $8 \mathrm{~K}$. Irradiation of the matrix with UV light $(254 \mathrm{~nm})$ produced the UV-vis spectrum of T-1b, characterized by maxima at $\lambda=228 \mathrm{~nm}, 281 \mathrm{~nm}, 312 \mathrm{~nm}$ and $380 \mathrm{~nm}$ (Figure 2 - black trace). ${ }^{39 \mathrm{a}}$ Upon annealing at $25 \mathrm{~K}$ and $35 \mathrm{~K}$ for $10 \mathrm{~min}$ each, new maxima appear at $\lambda=324 \mathrm{~nm}$ and $341 \mathrm{~nm}$ (Figure 2 - blue trace), which are assigned to dimer $\mathbf{5 b}$ by comparison with an authentic matrix isolated sample.

No other bands in the UV-vis region have been detected except those of $\mathbf{5 b}$. In an additional experiment, pentafluorophenylazide $\mathbf{2} \mathbf{b}$ was co-deposited with argon doped with $1 \%$ of $\mathrm{BF}_{3}$ in larger amount compared to the previous measurement. Irradiation with UV light at $\lambda=254 \mathrm{~nm}$ of such matrix generated T-1b, whose UV transitions cannot be detected anymore due to the signal saturation caused by the high concentration used. Upon annealing to $25 \mathrm{~K}$, a broad visible band appeared at $522 \mathrm{~nm}$, which increased remarkably in intensity after warming up the matrix at $35 \mathrm{~K}$. This visible band was assigned to the $c s S-1 . .2 \mathrm{BF}_{3}$, in agreement with TD-DFT calculations (M06-2X/6-311++G(d)) that predict a weak band in the visible region at $429 \mathrm{~nm}$ (Figure 2). Several arylnitrenium ions were produced by protonation of singlet arylnitrenes and studied by time resolved spectroscopy and in $\mathrm{HCl}$-doped argon matrices. ${ }^{39 \mathrm{~b}}$ These arylnitrenium ions also exhibit absorptions in the visible region, similar to that of $\operatorname{csS}-1 . .2 \mathrm{BF}_{3}$. 


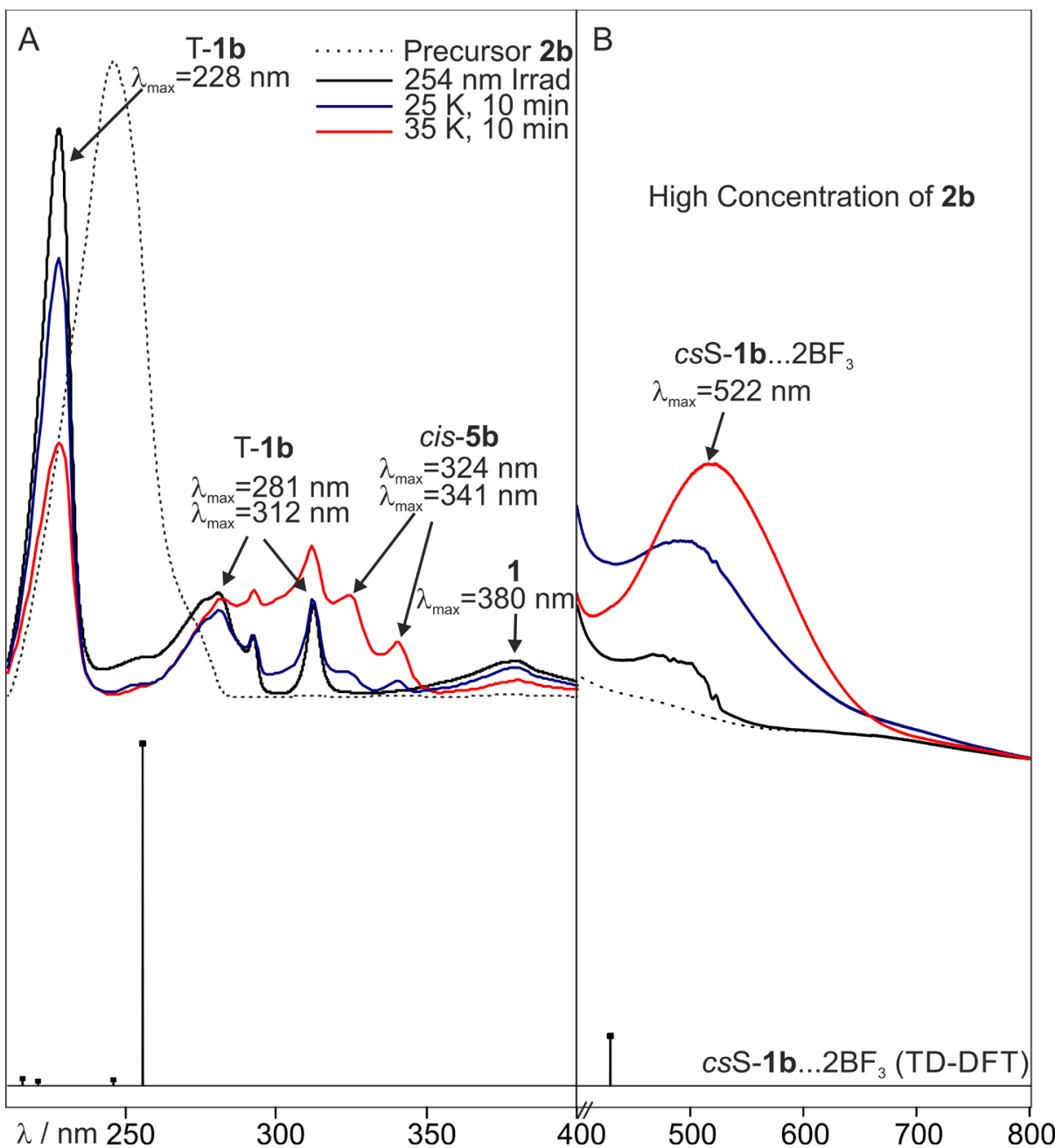

Figure 2. Panel A - UV-vis experiment with low concentration of pentafluorophenylazide 2b. Dotted line: UV-vis spectrum of pentafluorophenylazide $\mathbf{2} \mathbf{b}$ in an argon matrix doped with $1 \%$ of $\mathrm{BF}_{3}$. (Black line) UV-vis spectrum of T-1 $\mathbf{b}$ generated by photolysis of $\mathbf{2} \mathbf{b}$ with light at $\lambda=254$ nm. Blue line: $\mathrm{UV}$-vis spectrum of the same matrix after annealing from 8 to $25 \mathrm{~K}$ for 10 minutes. Red line: UV-vis spectrum of the same matrix after annealing to 35 $\mathrm{K}$ for 10 minutes. Panel B - UV-vis experiment with high concentration of pentafluorophenylazide 2b. Dotted line: UV-vis spectrum of pentafluorophenylazide $\mathbf{2} \mathbf{b}$ in an argon matrix doped with $1 \%$ of $\mathrm{BF}_{3}$. Black line: $\mathrm{UV}$-vis spectrum of $\mathrm{T}-\mathbf{1} \mathbf{b}$ generated by photolysis of $\mathbf{2} \mathbf{b}$ with light at $\lambda$ $=254 \mathrm{~nm}$. Blue line: UV-vis spectrum of the same matrix after annealing from 8 to $25 \mathrm{~K}$ for 10 minutes. Red line: UV-vis spectrum of the same matrix

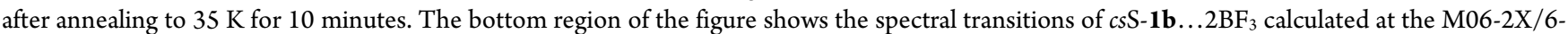
$311++\mathrm{G}(\mathrm{d})$ level of theory.

Calculations. The three electronic states of pentafluorophenyl nitrene $\mathrm{T}-\mathbf{1} \mathbf{b}$ were considered: the triplet ground state $\mathrm{T}-\mathbf{1} \mathbf{b}$ $\left({ }^{3} \mathrm{~A}_{2}\right)$, the open-shell singlet state os $\mathrm{S}-\mathbf{1} \mathbf{b}\left({ }^{1} \mathrm{~A}_{2}\right)$, and the closed-shell singlet state $c s S-1 \mathbf{b}\left({ }^{1} \mathrm{~A}_{1}\right)$, as well as their complexes with BF3. The energies of T-1b and csS-1b were calculated at the CCSD $(T) / 6-311++G(d) / / M 06-2 X / 6-311++G(d)$ level of theory, whereas the open shell singlet state osS-1b requires to use multireference methods, and therefore CASPT2 $(10,10) / 6-311 G G(d) / / C A S S C F(10,10) / 6-311 G(d)$ was used. These computations suggest that osS-1b lies 17.6 $\mathrm{kcal} / \mathrm{mol}$ and csS-1b even $25.7 \mathrm{kcal} / \mathrm{mol}$ above the triplet ground state T-1b (Figure 3). These values are similar to what was reported for the parent phenyl nitrene $\mathbf{1} \mathbf{a}^{40}$

$\operatorname{CCSD}(\mathrm{T})$ calculations of the $\mathrm{BF}_{3}$ complexes of nitrene $\mathbf{1} \mathbf{b}$ predict that the closed shell singlet complex $c s S-\mathbf{1} \mathbf{b} . . . \mathrm{BF}_{3}$ is stabilized by $24.6 \mathrm{kcal} / \mathrm{mol}$, while the triplet complex $\mathrm{T}-\mathbf{1 b} . . \mathrm{BF}_{3}$ is stabilized by only $5.2 \mathrm{kcal} / \mathrm{mol}$ for (Figure 3 ). As a result, the energy gap between T-1b and csS-1b is reduced from $25.7 \mathrm{kcal} / \mathrm{mol}$ in the free nitrene to only $6.3 \mathrm{kcal} / \mathrm{mol}$ in the complex, whereas the gap between T-1b and osS-1b remains still large at 17.6 and $19.5 \mathrm{kcal} / \mathrm{mol}$ with respect to the corresponding triplet complexes (Figure 3). The B-N distance in $c s S-\mathbf{1 b} \ldots \mathrm{BF}_{3}$ is $1.63 \AA$ (M06-2X/6-311++G(d)) similar to that in $\mathrm{H}_{3} \mathrm{~N}_{\text {....BF }}{ }_{3}{ }^{41}$ whereas in $\mathrm{T}-\mathbf{1 b} \ldots \mathrm{BF}_{3}$ it is considerably longer $(2.43 \AA$ ). Other structural parameters are also markedly different: the triplet complex $\mathrm{T}-\mathbf{1} \mathbf{b} \ldots \mathrm{BF}_{3}$ is linear with a C-N-B bond angle of $180^{\circ}$, whereas in $c s \mathrm{~S}-\mathbf{1} \mathbf{b} . . . \mathrm{BF}_{3}$ the C-N-B bond angle is $125.8^{\circ}$ and the boron atom lies in the ring plane (Figure 3). 


\begin{abstract}
Figure 3. Relative energies of the triplet and singlet complexes of $\mathbf{1 b}$ with one and two $\mathrm{BF}_{3}$ molecules at the $\mathrm{CCSD}(\mathrm{T}) / 6-311++\mathrm{G}(\mathrm{d}) / / \mathrm{M} 06-2 \mathrm{X} / 6$ $311++G(d)$ level of theory. The energy gap obtained at the CASPT2 $(10,10) / 6-311 G(d) / / C A S S C F(10,10) / 6-311 G(d)$ level of theory between triplet and open-shell singlet states of the nitrene and its complex with one BF3 molecule is represented in dashed blue. The structure of the crossing point between the singlet and triplet surfaces of complex $\mathbf{1 b} \ldots 2 \mathrm{BF}_{3}$ is shown in Figure $\mathrm{S} 10$ (SI).

The very different interaction of $\mathrm{BF}_{3}$ with $\mathrm{T}-\mathbf{1} \mathbf{b}$ and $c s \mathrm{~S}-\mathbf{1} \mathbf{b}$ can be also demonstrated by following the interaction energies between $\mathbf{1 b}$ and $\mathrm{BF}_{3}$ and the changes in hybridization of the lone pair at the nitrene center (Figure 4). For both $\mathrm{T}-\mathbf{1 b}$ and csS-1b the sigma orbital has a high s character of $70 \%$ and $65 \%$, respectively. Once the $\mathrm{BF}_{3}$ molecule approaches, the $s$ character in csS- $\mathbf{1 b}$ is drastically reduced to $33 \%$ by efficient rehybridization with the doubly filled $\mathrm{p}_{\mathrm{x}}$ orbital, resulting in two $\mathrm{sp}_{2}$ orbitals. This rehybridization is also reflected in the C-N-B bond angle in the complex of $125.8^{\circ}$. The hybridization of the approaching $\mathrm{BF}_{3}$ molecule changes in a similar way from $\mathrm{sp}_{2}$ in the initial stage to $\mathrm{sp}_{3}$ in the final complex, resulting in a strong pyramidalization of $\mathrm{BF}_{3}$ in $c s \mathrm{~S}-\mathbf{1} \mathbf{b} . . . \mathrm{BF}_{3}$ and a very large energetic stabilization. In $\mathrm{T}-\mathbf{1} \mathbf{b}$, the rehybridization of the nitrene lone pair is not possible, and the $\mathrm{s}$ character remains at $70 \%$, irrespective of the $\mathrm{B}-\mathrm{N}$ distance. $\mathrm{The} \mathrm{BF}_{3}$ molecule approaches the nitrene along the B-N axis, and the resulting stabilization energy is small.
\end{abstract}




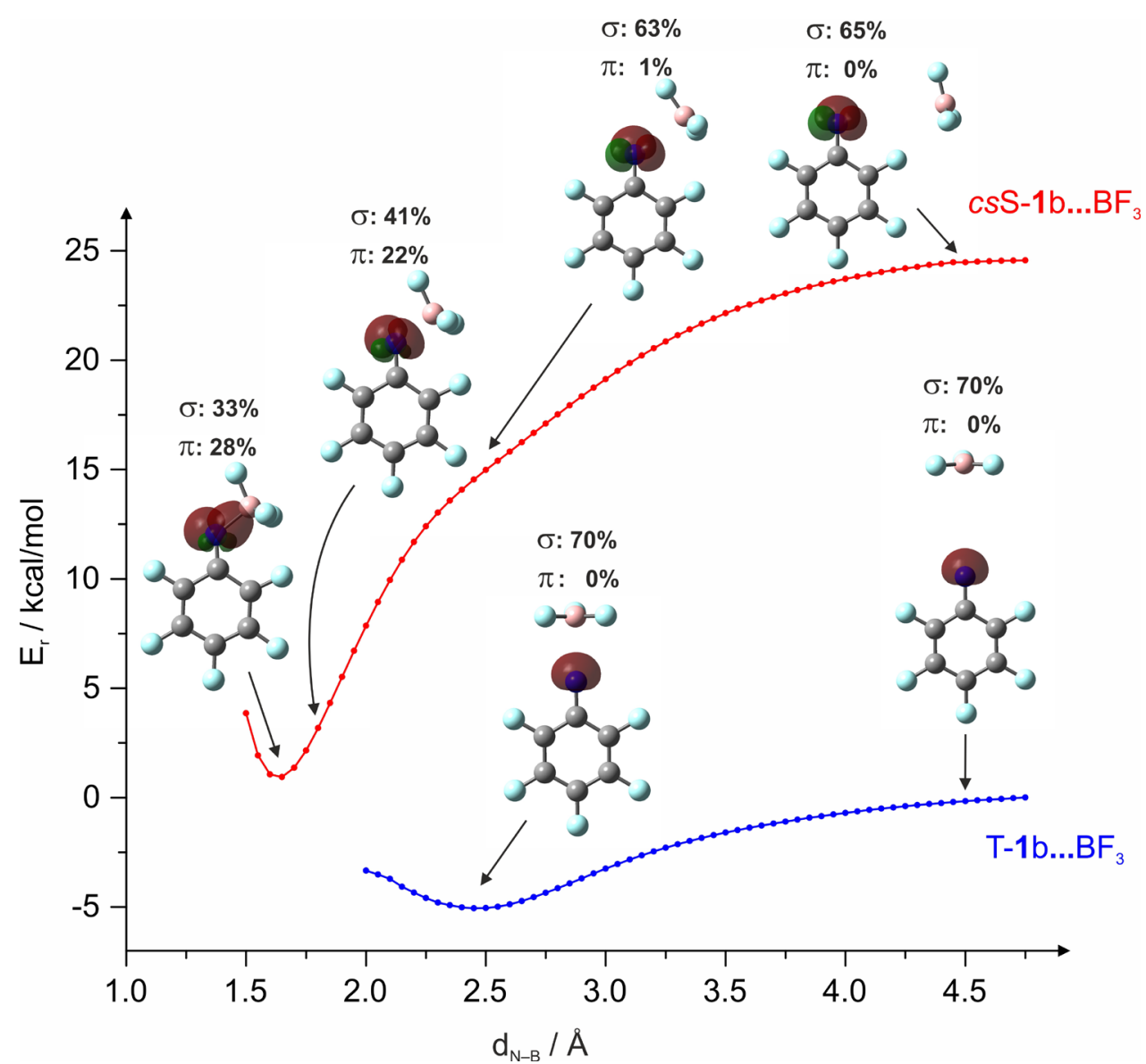

Figure 4. Relax scan of the energy of $c s \mathrm{~S}-\mathbf{1} \mathbf{b} \ldots \mathrm{BF}_{3}$ and $\mathrm{T}-\mathbf{1} \mathbf{b} \ldots \mathrm{BF}_{3}$ along the $\mathrm{C}-\mathrm{B}$ distance. Plot and s-character of the doubled-occupied $\mathrm{NBMOs}$ are shown at selected points to visualize the rehybridization of the orbitals at the $\mathrm{N}$ center of $\mathrm{S}-\mathbf{1} \mathrm{b}$, upon complexation with $\mathrm{BF}_{3}$. Energies and electronic properties were calculated at the $(\mathrm{U}) \mathrm{M} 06-2 \mathrm{X} / 6-311++\mathrm{G}(\mathrm{d})$ level of theory.

The interaction energy $\Delta \mathrm{E}$ between the nitrene $\mathbf{1 b}$ and a $\mathrm{BF}_{3}$ molecule can be partitioned into the deformation $\left(\mathrm{E}_{\mathrm{N}}+\mathrm{E}_{\mathrm{BF}_{3}}\right)$ and instantaneous energies $\left(\mathrm{E}_{\mathrm{int}}\right)_{4}{ }^{22-43}$

$\Delta \mathrm{E}=\mathrm{E}_{\text {int }}+\left(\mathrm{E}_{\mathrm{N}}+\mathrm{E}_{\mathrm{BF} 3}\right)$

$\mathrm{E}_{\mathrm{N}}$ and $\mathrm{E}_{\mathrm{BF}_{3}}$ are the energies required to deform the nitrene and the $\mathrm{BF}_{3}$ from their relaxed nuclear configurations to the geometries in the complex. $E_{\text {int }}$ is the instantaneous interaction energy of the deformed fragments in the complex (Table 1). Since in the triplet complex $\mathrm{T}-\mathbf{1} \mathbf{b} \ldots \mathrm{BF}_{3}$ the fragments are only very slightly deformed compared to the non-interacting fragments, $\mathrm{E}_{\text {int }}$ is with $-6.0 \mathrm{kcal} / \mathrm{mol}$ only by $0.8 \mathrm{kcal} / \mathrm{mol}$ more negative than $\Delta \mathrm{E}$. For $\mathrm{S}-\mathbf{1 b} \ldots \mathrm{BF}_{3}$, the energy required for the deformation of the nitrene $\left(\mathrm{E}_{\mathrm{N}}=2.4 \mathrm{kcal} / \mathrm{mol}\right)$ and the $\mathrm{BF}_{3}\left(\mathrm{E}_{\mathrm{BF}_{3}}=26.9 \mathrm{kcal} / \mathrm{mol}\right)$ is much larger, however, more than compensated by the huge $\mathrm{E}_{\text {int }}$ of $-53.9 \mathrm{kcal} / \mathrm{mol}$. The interaction energy $\Delta \mathrm{E}$ of $c s S-1 \mathbf{b} \ldots \mathrm{BF}_{3}$ is very similar to that of ammonia borane $\mathrm{N}_{3} \mathrm{H} \ldots \mathrm{BF}_{3}$, while the intrinsic interaction energy $\mathrm{E}_{\text {int }}$ is even higher (Table 1). This indicates that the closed-shell singlet state $c s \mathrm{~S}-\mathbf{1} \mathbf{b}$ acts as a strong Lewis base, comparable to ammonia, whereas $\mathrm{T}-\mathbf{1 b}$ is only weakly basic.

Table 1. Deformation of the BF3 fragment and energetics of Lewis acid-base complexes.

\begin{tabular}{lccccc}
\hline & $\angle \mathrm{FFFB}$ & $\mathrm{E}_{\mathrm{N}}$ & $\mathrm{E}_{\mathrm{BF} 3}$ & $\mathrm{E}_{\text {int }}$ & $\Delta \mathrm{E}$ \\
\hline $\mathrm{NH}_{3} \ldots \mathrm{BF}_{3}$ & $26.6^{\circ}$ & 0.1 & 23.0 & -47.3 & -24.2 \\
$c s \mathrm{-1} \mathbf{b} \ldots \mathrm{BF}_{3}$ & $28.5^{\circ}$ & 2.4 & 26.9 & -53.9 & -24.6 \\
$\mathrm{~T}-\mathbf{1} \mathbf{b} \ldots \mathrm{BF}_{3}$ & $5.0^{\circ}$ & 0.2 & 0.6 & -6.0 & -5.2
\end{tabular}

Complexation energy between the fragments $(\Delta \mathrm{E})$ partitioned into interaction energy of the frozen fragments $\left(\mathrm{E}_{\text {int }}\right)$ and deformation energy of the base fragment $\left(\mathrm{E}_{\mathrm{N}}\right)$ and the $\mathrm{BF} 3$ fragment $\left(\mathrm{E}_{\mathrm{BF} 3}\right)$. Energies were calculated at the $\operatorname{CCSD}(\mathrm{T}) / 6-311++\mathrm{G}(\mathrm{d}) / / \mathrm{M} 06-2 \mathrm{X} / 6-311++\mathrm{G}(\mathrm{d})$ level of theory and are given in $\mathrm{kcal} / \mathrm{mol}$. The FFFB dihedral angle correspond to the angle between the FFF and FFB intersecting planes and has a zero value for the nondistorted BF3 molecule. 
These calculations indicate that forming the $\mathrm{BF}_{3}$ complex drastically reduces the $\mathrm{S}$ - $\mathrm{T}$ gap of nitrene $\mathbf{1 b}$, however, not enough to switch the ground state of the nitrene complex to singlet. Thus, to achieve a singlet ground state Lewis acid-base complex of $\mathbf{1 b}$, a stronger Lewis acid than $\mathrm{BF}_{3}$ is required.

Scheme 2. Reaction of pentafluoronitrene $1 \mathrm{~b}$ with $\mathrm{BF}_{3}$ and structure of $S-11 \ldots 2 \mathrm{BF}_{3}$.

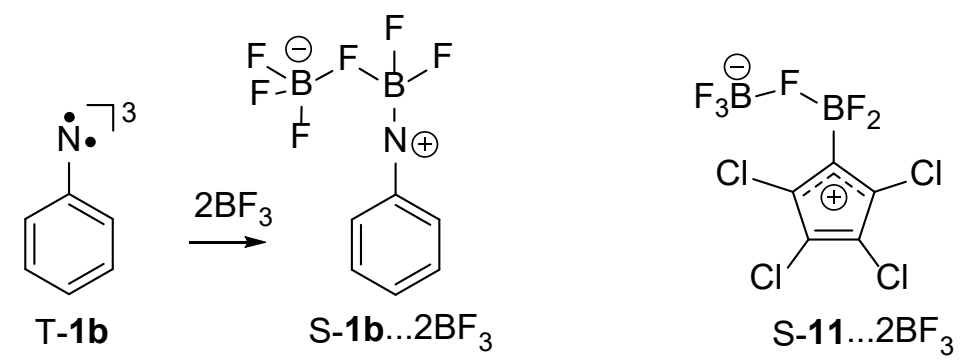

We recently observed that the Lewis acidity of $\mathrm{BF}_{3}$ in a carbene complex increases by adding a second $\mathrm{BF}_{3}$ molecule to the complex resulting in ternary complexes. ${ }^{44}$ In the complex between tetrachlorocyclopentadienylidene $S-11$ and two molecules of $\mathrm{BF}_{3}$, the second $\mathrm{BF}_{3}$ interacts with the first $\mathrm{BF}_{3}$ via a strong B-F-B fluoronium bridge, but does not directly interact with the carbene as Lewis base (Scheme 2). In a very similar way, the singlet state csS-1b forms a ternary complex csS- $1 \mathbf{b} \ldots 2 \mathrm{BF}_{3}$ with two molecules of $\mathrm{BF}_{3}$ in which one of the $\mathrm{BF}_{3}$ molecules is directly interacting with the nitrene center of csS-1b, while the second $\mathrm{BF}_{3}$ is attached to the first via a B-F-B fluoronium bridge (Figure 5). In csS- $\mathbf{1 b} \ldots 2 \mathrm{BF}_{3}, \mathrm{the}^{\mathrm{BF}_{3}}$ molecule directly interacting with $\mathbf{1 b}$ adopts a quasi-tetrahedral geometry with B-F bonds considerably longer than in the isolated $\mathrm{BF}_{3}$ molecule. The bridging $\mathrm{F}$ atom is almost equally shared between the two boron atoms, resulting in a less negative partial charge at this fluorine atom compared to the other fluorine atoms (see electrostatic potential in Figure 5 and natural charges in Figure S9, SI). Furthermore, one of the fluorine atoms of the second $\mathrm{BF}_{3}$ molecule donates electron density to the empty $\pi$ orbital in the nitrene, resulting in additional stabilization of the ternary complex. The stabilization of $\operatorname{csS}-\mathbf{1 b} \ldots 2 \mathrm{BF}_{3}$ is with $39.3 \mathrm{kcal} / \mathrm{mol}$ large enough to become more stable (by $2.2 \mathrm{kcal} / \mathrm{mol}$ ) than the triplet complex $\mathrm{T}-\mathbf{1} \mathbf{b} . . .2 \mathrm{BF}_{3}$, thus switching the ground state of the complex from triplet to singlet (Figure 3), in accordance with our experimental results.

$\operatorname{csS}-1 \mathrm{~b} . . .2 \mathrm{BF}_{3}$
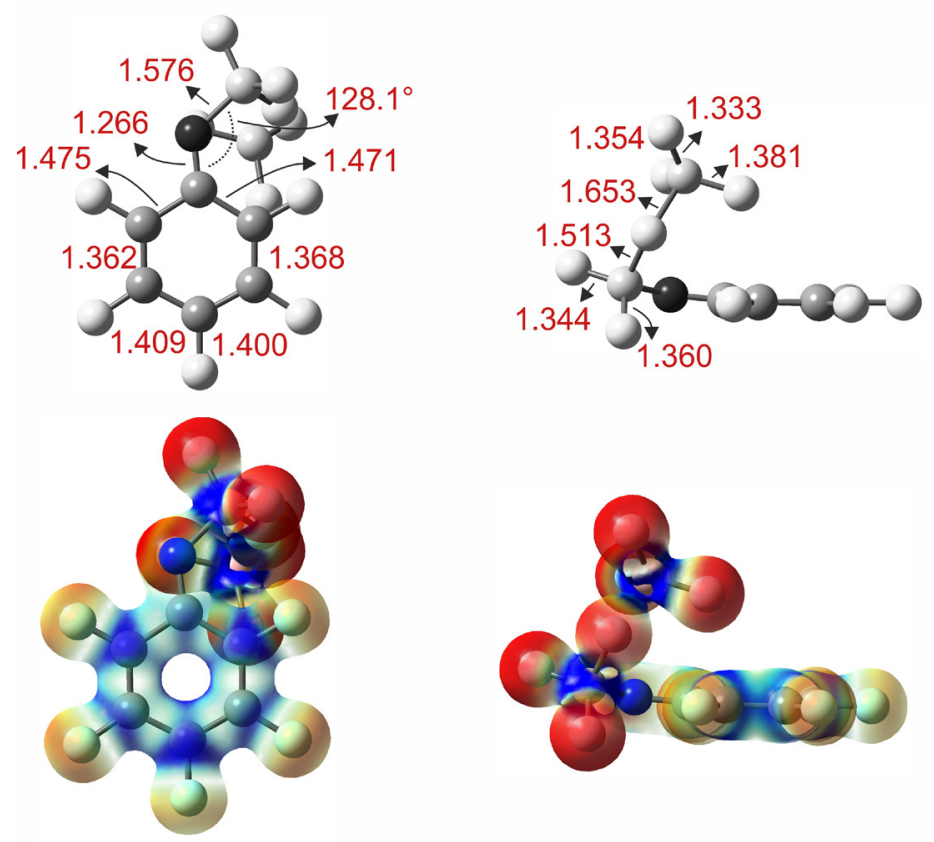

Figure 5. Some structural parameters of the optimized structure of $c s S-1 \mathbf{b} \ldots 2 \mathrm{BF}_{3}$ computed at the M06-2X/6-311++G(d) level of theory. Plots of the electrostatic potential (isosurface value 0.05 ) are shown below (blue: positive potential, red: negative potential). 


\section{Conclusions}

The chemistry of arylnitrenes is dominated by open-shell triplet and singlet states frequently resulting in unwanted polymeric byproducts. ${ }^{13,45}$ The strategy presented here to overcome this deficiency is to stabilize the closed-shell singlet states by interactions with strong Lewis acids. Although in arylnitrenes all three relevant electronic states - the triplet, the open shell singlet, and the closed shell singlet state - have lone pairs at the nitrene center and thus principally could act as Lewis base, only the closed shell singlet state shows the required strong Lewis basicity. In the open shell triplet and singlet states the lone pair occupies an orbital rich in $2 s$ character and thus low in energy., ${ }^{8}{ }^{46}$ Consequently, these states are only weakly stabilized by interactions with a Lewis acid. In contrast, the second (perpendicular) lone pair in csS-1b is high in energy with a large $\mathrm{p}$ character. Interaction with $\mathrm{BF}_{3}$ results in a re-hybridization to give two in-plane lone pairs of nearly $\mathrm{sp}^{2}$ character. Therefore, $c s S-\mathbf{1 b}$ exhibits strong Lewis basicity, comparable to that of ammonia. However, the strong interaction with $\mathrm{BF}_{3}$ is not sufficient to stabilize the closed shell singlet state $c s S-\mathbf{1 b}$ below the triplet state $\mathrm{T}-\mathbf{1} \mathbf{b}$, and thus in the experiment only a weakly interacting triplet complex is formed.

To achieve a singlet ground state, it is necessary that the nitrene interacts with two molecules of $\mathrm{BF}_{3}$. This is realized by doping matrices with higher concentrations of $\mathrm{BF}_{3}$ and by prolonged annealing the matrices at temperatures where $\mathrm{BF}_{3}$ is able to diffuse. Under these conditions, the red color (corresponding to the $522 \mathrm{~nm}$ absorption) of $c s \mathrm{~S}-\mathbf{1 b} \ldots 2 \mathrm{BF}_{3}$ appears and the characteristic EPR signals of T-1b disappear. The formation of the ternary complex csS-1 $\mathbf{b} \ldots 2 \mathrm{BF}_{3}$ can also be monitored by IR spectroscopy. Similar ternary complexes with two molecules of $\mathrm{BF}_{3}$ interacting via a fluoronium bridge were observed when the matrix-isolated triplet ground state tetrachlorocyclopentadienylidene $\mathbf{1} \mathbf{1}$ was allowed to interact with an excess of $\mathrm{BF}_{3}$. The major difference between this carbene and nitrene $\mathbf{1 b}$ is the much larger singlet-triplet splitting $\Delta \mathrm{E}_{\mathrm{ST}}$ in the nitrene. Consequently, interaction with one molecule of $\mathrm{BF}_{3}$ with the carbenes is enough to stabilize the singlet states of the Lewis acid-base complexes of carbenes, whereas two molecules of $\mathrm{BF}_{3}$ are necessary for the nitrene. The resulting ternary complex csS- $1 \mathbf{b} \ldots 2 \mathrm{BF}_{3}$ is highly polar with the nitrene moiety resembling a nitrenium ion. ${ }^{39 \mathrm{~b}}$

These results demonstrate that the closed shell singlet states of aryl nitrenes become accessible by Lewis acid-base interactions. However, very strong Lewis acids are necessary to overcome the large singlet - triplet gap in arylnitrenes. It remains to be proven that this method can be applied to solution phase chemistry.

\section{EXPERMENTAL SECTION}

Synthesis. Pentafluorophenylazide $\mathbf{2 b}$ was synthesized according to a literature procedure.

Matrix isolation spectroscopy. Matrix isolation experiments were performed using standard techniques as reported previously. ${ }^{30,32,34}$ Matrices were generated by co-deposition of pentafluorophenylazide $\mathbf{2} \mathbf{b}$ and $1 \%$ of $\mathrm{BF}_{3}$ with a large excess of argon (99.99\%). The matrices were irradiated at $254 \mathrm{~nm}$ using a low pressure mercury arc lamp.

Computational details. Gas-phase geometry optimizations and frequency calculations were performed using the M06-2x functional ${ }^{47}$ employing the 6-311++G(d,p) basis set ${ }^{48,49}$ as implemented in Gaussian 09 (Revision D.01). ${ }^{50}$ Multirreference calculations were performed at the CASPT2 $(10,10) / 6-311 G(d) / / \operatorname{CASSCF}(10,10) / 6-311 \mathrm{G}(\mathrm{d})$ level of theory, using state average for the singlets states, as implemented in Molpro. ${ }^{51}$

\section{Supporting Information}

Additional spectroscopic and computational data. "This material is available free of charge via the Internet at http://pubs.acs.org."

\section{AUTHOR INFORMATION}

\section{Corresponding Author}

Wolfram.sander@rub.de

\section{Notes}

The authors declare no competing financial interests. 


\section{ACKNOWLEDGMENT}

This work was supported by the Cluster of Excellence RESOLV (EXC 1069) funded by the Deutsche Forschungsgemeinschaft (DFG).

\section{REFERENCES}

1. Gritsan, N. P.; Platz, M. S., Kinetics, Spectroscopy, and Computational Chemistry of Arylnitrenes. Chem. Rev. 2006, 106 (9), $3844-3867$.

2. Plate, M. S., Photoaffinity Labeling Introduction. Photochem. Photobiol. 1997, 65, 193-194.

3. Morishita, H.; Ito, M.; Hayashi, N.; Nonogaki, S.; Odaka, Y.; Nishizawa, M., A new water-soluble photoresist used a polymeric azide compound as a photosensitizer. J. Photopolym. Sci. Technol. 1994, 7, 59-66.

4. Chapter 2 Photogenerated reactive intermediates and their properties. In Laboratory Techniques in Biochemistry and Molecular Biology, BURDON, T. S. W. a. R. H., Ed. Elsevier: 1983; Vol. Volume 12, pp 8-24.

5. Misochko, E. Y.; Korchagin, D. V.; Bozhenko, K. V.; Chapyshev, S. V.; Aldoshin, S. M., A density functional theory study of the zero-field splitting in high-spin nitrenes. J. Chem. Phys. 2010, 133, 064101.

6. Nimura, S.; Yabe, A., Use of dinitrenes as models for intramolecular exchange. Magnetic Properties of Organic Materials 1999, 127-145.

7. Mieres-Pérez, J.; Henkel, S.; Mendez-Vega, E.; Schleif, T.; Lohmiller, T.; Savitsky, A.; Sander, W., Dinitreno pentaradicals: organic sextet molecules. J. Phys. Org. Chem. 2017, 30, e3621.

8. Borden, W. T.; Gritsan, N. P.; Hadad, C. M.; Karney, W. L.; Kemnitz, C. R.; Platz, M. S., The Interplay of Theory and Experiment in the Study of Phenylnitrene. Acc. Chem. Res. 2000, 33, 765-771.

9. Platz, M. S., Comparison of Phenylcarbene and Phenylnitrene. Acc. Chem. Res. 1995, 28, 487-492.

10. Mieres-Pérez, J.; Mendez-Vega, E.; Velappan, K.; Sander, W., Reaction of Triplet Phenylnitrene with Molecular Oxygen. J. Org. Chem. 2015, 80, 11926-11931.

11. Kvaskoff, D.; Luerssen, H.; Bednarek, P.; Wentrup, C., Phenylnitrene, Phenylcarbene, and Pyridylcarbenes. Rearrangements to Cyanocyclopentadiene and Fulvenallene. J. Am. Chem. Soc. 2014, 136, 15203-15214.

12. Wentrup, C., Thermochemistry of Carbene and Nitrene Rearrangements. Tetrahedron 1974, 30, 1301-1311.

13. Platz, M. S., Comparison of Phenylcarbene and Phenylnitrene. Acc. Chem. Res. 1995, 28, 487-92.

14. Smolinsky, G.; Wasserman, E.; Yager, W. A., Epr of Ground State Triplet Nitrenes. J. Am. Chem. Soc. 1962, 84, 3220.

15. Mieres-Perez, J.; Mendez-Vega, E.; Velappan, K.; Sander, W., Reaction of Triplet Phenylnitrene with Molecular Oxygen. J. Org. Chem. 2015, 80, 11926-11931.

16. Wentrup, C., Nitrenes, Carbenes, Diradicals, and Ylides. Interconversions of Reactive Intermediates. Acc. Chem. Res. 2011, 44, 393-404.

17. Karney, W. L.; Borden, W. T., Ab initio study of the ring expansion of phenylnitrene and comparison with the ring expansion of phenylcarbene. J. Am. Chem. Soc. 1997, 119, 1378-1387.

18. Wijeratne, N. R.; Da Fonte, M.; Ronemus, A.; Wyss, P. J.; Tahmassebi, D.; Wenthold, P. G., Photoelectron spectroscopy of chloro-substituted phenylnitrene anions. J. Phys. Chem. A 2009, 113, 9467-73.

19. Tsao, M.-L.; Platz, M. S., Photochemistry of Ortho, Ortho' Dialkyl Phenyl Azides. J. Am. Chem. Soc. 2003, 125, 12014-12025.

20. Johnson, W. T. G.; Sullivan, M. B.; Cramer, C. J., Meta and para substitution effects on the electronic state energies and ring-expansion reactivities of phenylnitrenes. Int. J. Quantum Chem. 2001, 85, 492-508.

21. Gritsan, N. P.; Yuzawa, T.; Platz, M. S., Direct Observation of Singlet Phenyl nitrene and Measurement of Its Rate of Rearrangement. J. Am. Chem. Soc. 1997, 119, 5059-5060.

22. Born, R.; Burda, C.; Senn, P.; Wirz, J., Transient Absorption Spectra and Reaction Kinetics of Singlet Phenyl nitrene and Its 2,4,6-Tribromo Derivative in Solution. J. Am. Chem. Soc. 1997, 119, 5061-5062.

23. Winkler, M., Singlet-triplet energy splitting and excited states of phenylnitrene. J. Phys. Chem. A 2008, 112, 8649-53.

24. Wenthold, P. G., Spin-State Dependent Radical Stabilization in Nitrenes: The Unusually Small Singlet-Triplet Splitting in 2-Furanylnitrene. J. Org. Chem. 2012, 77, 208-214.

25. Li, H.; Wu, Z.; Li, D.; Zeng, X.; Beckers, H.; Francisco, J. S., Singlet thiophosphoryl nitrene and interconversion with thiazyl and thionitroso isomers. J. Am. Chem. Soc. 2015, 137, 10942-10945.

26. Pritchina, E. A.; Gritsan, N. P.; Maltsev, A.; Bally, T.; Autrey, T.; Liu, Y. L.; Wang, Y. H.; Toscano, J. P., Matrix isolation, time-resolved IR, and computational study of the photochemistry of benzoyl azide. Phys. Chem. Chem. Phys. 2003, 5, 1010-1018.

27. Kubicki, J.; Zhang, Y. L.; Vyas, S.; Burdzinski, G.; Luk, H. L.; Wang, J.; Xue, J. D.; Peng, H. L.; Pritchina, E. A.; Sliwa, M.; Buntinx, G.; Gritsan, N. P.; Hadad, C. M.; Platz, M. S., Photochemistry of 2-Naphthoyl Azide. An Ultrafast Time-Resolved UV-Vis and IR Spectroscopic and Computational Study. J. Am. Chem. Soc. 2011, 133, 9751-9761.

28. Feng, R.; Lu, Y.; Deng, G.; Xu, J.; Wu, Z.; Li, H.; Liu, Q.; Kadowaki, N.; Abe, M.; Zeng, X., Magnetically Bistable Nitrenes: Matrix Isolation of Furoylnitrenes in Both Singlet and Triplet States and Triplet 3-Furylnitrene. J. Am. Chem. Soc. 2018, 140, 10-13.

29. Dielmann, F.; Back, O.; Henry-Ellinger, M.; Jerabek, P.; Frenking, G.; Bertrand, G., A Crystalline Singlet Phosphinonitrene: A Nitrogen AtomTransfer Agent. Science 2012, 337, 1526.

30. Costa, P.; Fernandez-Oliva, M.; Sanchez-Garcia, E.; Sander, W., The Highly Reactive Benzhydryl Cation Isolated and Stabilized in Water Ice. J. Am. Chem. Soc. 2014, 136, 15625-30.

31. Costa, P.; Trosien, I.; Fernandez-Oliva, M.; Sanchez-Garcia, E.; Sander, W., The Fluorenyl Cation. Angew. Chem. Int. Ed. 2015, 54, $2656-2660$.

32. Costa, P.; Sander, W., Hydrogen Bonding Switches the Spin State of Diphenylcarbene from Triplet to Singlet. Angew. Chem. Int. Ed. 2014, 53, 5122-5125. 
33. Knorr, J.; Sokkar, P.; Schott, S.; Costa, P.; Thiel, W.; Sander, W.; Sanchez-Garcia, E.; Nuernberger, P., Competitive solvent-molecule interactions govern primary processes of diphenylcarbene in solvent mixtures. Nat. Commun. 2016, 7, 12968.

34. Henkel, S.; Costa, P.; Klute, L.; Sokkar, P.; Fernandez-Oliva, M.; Thiel, W.; Sanchez-Garcia, E.; Sander, W., Switching the Spin State of Diphenylcarbene via Halogen Bonding. J. Am. Chem. Soc. 2016, 138, 1689-1697.

35. (a) Costa, P.; Perez, J. M.; Oezkan, N.; Sander, W., Activation of the B-F Bond by Diphenylcarbene: A Reversible 1,2-Fluorine Migration between Boron and Carbon. Angew. Chem., Int. Ed. 2017, 56, 1760-1764. (b) Costa, P.; Trosien, I.; Mieres-Perez, J.; Sander, W., Isolation of an Antiaromatic Singlet Cyclopentadienyl Zwitterion. J. Am. Chem. Soc. 2017, 139, 13024-13030.

36. (a) Zanirato, P., The reaction of organic azides with boron trichloride: a new simple route for the production of fused heterocycles containing nitrogen. J. Chem. Soc., Chem. Commun. 1983, 1065-1067. (b) Zanirato, P., Synthesis, reactivity, and electronic structure of multifarious, fivemembered heteroaryl and heteroaroyl azides. Arkivoc, 2009, 97-128.

37. Morawietz, J.; Sander, W., Photochemistry of Fluorinated Phenyl Nitrenes: Matrix Isolation of Fluorinated Azirines. J. Org. Chem. 1996, 61, 4351-4354.

38. Costa, P.; Mieres-Perez, J.; Özkan, N.; Sander, W., Activation of the B-F Bond by Diphenylcarbene: A Reversible 1,2-Fluorine Migration between Boron and Carbon. Angewandte Chemie International Edition 2017, 56, 1760-1764.

39. (a) Leyva, E.; Platz, M. S.; Persy, G.; Wirz, J., Photochemistry of phenyl azide: the role of singlet and triplet phenylnitrene as transient intermediates. J. Am. Chem. Soc. 1986, 108, 3783-3790. (b) Wang, J.; Burdzinski, G.; Zhu, Z. D.; Platz, M. S.; Carra, C.; Bally, T., Ultrafast spectroscopic and matrix isolation studies of p-biphenylyl, o-biphenylyl, and 1-naphthylnitrenium cations. J. Am. Chem. Soc. 2007, $129,8380-8388$.

40. Winkler, M., Singlet-Triplet Energy Splitting and Excited States of Phenylnitrene. J. Phys. Chem. A 2008, 112, 8649-8653.

41. Jonas, V.; Frenking, G., Studies on the boron-nitrogen bond length of the classical donor-acceptor complex H3N-BF3. J. Chem. Soc., Chem. Commun. 1994, 1489-1490.

42. Jonas, V.; Frenking, G.; Reetz, M. T., Comparative Theoretical Study of Lewis Acid-Base Complexes of $\mathrm{BH}_{3}, \mathrm{BF}_{3}, \mathrm{BCl}_{3}, \mathrm{AlCl}_{3}$, and $\mathrm{SO}_{2}$. J. Am Chem. Soc. 1994, 116, 8741-8753.

43. Bessac, F.; Frenking, G., Why Is $\mathrm{BCl}_{3}$ a Stronger Lewis Acid with Respect to Strong Bases than $\mathrm{BF}_{3}$ ? Inorg. Chem. 2003, 42, $7990-7994$.

44. Costa, P.; Trosien, I.; Mieres-Perez, J.; Sander, W., Isolation of an Antiaromatic Singlet Cyclopentadienyl Zwitterion. Journal of the American Chemical Society 2017, 139, 13024-13030.

45. Meijer, E. W.; Nijhuis, S.; Van Vroonhoven, F. C. B. M., Poly-1,2-azepines by the photopolymerization of phenyl azides. Precursors for conducting polymer films. J. Am. Chem. Soc. 1988, 110, 7209-7210.

46. Kemnitz, C. R.; Karney, W. L.; Borden, W. T., Why are nitrenes more stable than carbenes? An ab initio study. J. Am. Chem. Soc. 1998, 120, 3499-3503.

47. Zhao, Y.; Truhlar, D. G., The M06 suite of density functionals for main group thermochemistry, thermochemical kinetics, noncovalent interactions, excited states, and transition elements: two new functionals and systematic testing of four M06-class functionals and 12 other functionals. Theor. Chem. Acc. 2008, 120, 215-241.

48. Self-consistent molecular orbital methods. XX. A basis set for correlated wave functions. The Journal of Chemical Physics 1980, $72,650-654$.

49. McLean, A. D.; Chandler, G. S., Contracted Gaussian basis sets for molecular calculations. I. Second row atoms, Z=11-18. The Journal of Chemical Physics 1980, 72, 5639.

50. Frisch, M. J.; Trucks, G. W.; Schlegel, H. B.; Scuseria, G. E.; Robb, M. A.; Cheeseman, J. R.; Scalmani, G.; Barone, V.; Mennucci, B.; Petersson, G. A.; Nakatsuji, H.; Caricato, M.; Li, X.; Hratchian, H. P.; Izmaylov, A. F.; Bloino, J.; Zheng, G.; Sonnenberg, J. L.; Hada, M.; Ehara, M.; Toyota, K.; Fukuda, R.; Hasegawa, J.; Ishida, M.; Nakajima, T.; Honda, Y.; Kitao, O.; Nakai, H.; Vreven, T.; Montgomery, J., J. A.; Peralta, J. E.; Ogliaro, F.; Bearpark, M.; Heyd, J. J.; Brothers, E.; Kudin, K. N.; Staroverov, V. N.; Kobayashi, R.; Normand, J.; Raghavachari, K.; Rendell, A.; Burant, J. C.; Iyengar, S. S.; Tomasi, J.; Cossi, M.; Rega, N.; Millam, J. M.; Klene, M.; Knox, J. E.; Cross, J. B.; Bakken, V.; Adamo, C.; Jaramillo, J.; Gomperts, R.; Stratmann, R. E.; Yazyev, O.; Austin, A. J.; Cammi, R.; Pomelli, C.; Ochterski, J. W.; Martin, R. L.; Morokuma, K.; Zakrzewski, V. G.; Voth, G. A.; Salvador, P.; Dannenberg, J. J.; Dapprich, S.; Daniels, A. D.; Farkas, Ö.; Foresman, J. B.; Ortiz, J. V.; Cioslowski, J.; Fox, D. J., Gaussian 09 Revision D.01.

51. MOLPRO, version 2012.1, a package of ab initio programs, H.-J. Werner, P. J. Knowles, G. Knizia, F. R. Manby, M. Schütz, P. Celani, T. Korona, R. Lindh, A. Mitrushenkov, G. Rauhut, K. R. Shamasundar, T. B. Adler, R. D. Amos, A. Bernhardsson, A. Berning, D. L. Cooper, M. J. O. Deegan, A. J. Dobbyn, F. Eckert, E. Goll, C. Hampel, A. Hesselmann, G. Hetzer, T. Hrenar, G. Jansen, C. Köppl, Y. Liu, A. W. Lloyd, R. A. Mata, A. J. May, S. J. McNicholas, W. Meyer, M. E. Mura, A. Nicklass, D. P. O'Neill, P. Palmieri, D. Peng, K. Pflüger, R. Pitzer, M. Reiher, T. Shiozaki, H. Stoll, A. J. Stone, R. Tarroni, T.

Thorsteinsson, and $M$. Wang, see http://www.molpro.net. . 
TOC Graphics
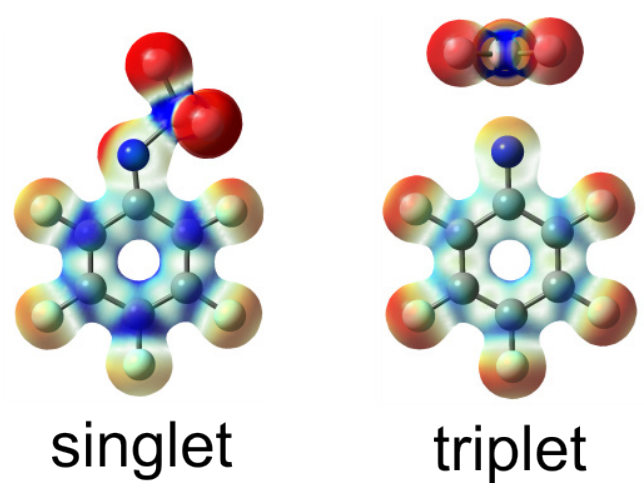

triplet 